Cita: Marques, G.1, Carraça, E.V. (2020). Efeitos psicológicos da música em praticantes de exercício: Uma revisão sistemática. Cuadernos de Psicología del Deporte, 20(2), 152-173

\title{
Efeitos psicológicos da música em praticantes de exercício: Uma revisão sistemática
}

\section{Efectos psicológicos de la música en practicantes de ejercicio: Una revisión sistemática}

\section{The psychological effects of music in exercisers: A systematic review}

\author{
Marques, G.1, Carraça, E.V.1,2 \\ 1Faculdade de Educação Física e Desporto, Universidade Lusófona de Humanidades e Tecnologias;2 \\ Centro Interdisciplinar de Estudo da Performance Humana (CIPER), Faculdade de Motricidade \\ Humana, Universidade de Lisboa
}

\begin{abstract}
RESUMO
Objetivo: Esta revisão sistemática teve o objetivo de sumariar a evidência existente sobre o efeito da presença de música durante a prática de exercício estruturado na motivação, vitalidade, resposta afetiva ao exercício e perceção subjetiva de esforço, entre outros fatores psicológicos, em praticantes regulares de exercício. Métodos: A pesquisa de artigos publicados até Janeiro de 2018 foi feita em 3 bases de dados (Pubmed, PsycINFO e SPORTDiscus), seguindo o modelo PICO, e complementada manualmente. A seguinte informação foi extraída dos artigos selecionados: tipo de estudo, características da intervenção, música (condição e instrumentos), outcomes (e instrumentos), resultados e qualidade metodológica. Esta última foi avaliada através do Quality Assessment Tool for Quantitative Studies. Resultados: Foram incluídos 27 artigos. Destes, 4 reportaram efeitos na motivação, 11 na resposta afetiva ao esforço, 22 na perceção subjetiva de esforço e 5 nas componentes motivacionais da música. A presença de música mostrou-se positivamente associada a maiores níveis de motivação ( $n=3$ de 4$)$, a uma resposta afetiva ao exercício aparentemente mais positiva ( $n=6$ de 11), mas na generalidade não se mostrou associada a menores níveis de perceção de esforço $(n=14$ de 22). Conclusão: Apesar da presença de música aparentar ter um efeito potencialmente positivo no nível de motivação e na resposta afetiva ao esforço, a variabilidade das amostras, dos protocolos de investigação e dos instrumentos utilizados na aferição das variáveis impossibilitam a retirada de conclusões, sublinhando a necessidade de novos estudos sobre esta temática. Palavras chave: Música, exercício, motivação, afeto, perceção de esforço.
\end{abstract}




\title{
Efeitos psicológicos da música em praticantes de exercício
}

\begin{abstract}
RESUMEN
Objetivo: Esta revisión sistemática tuvo como objetivo resumir la evidencia disponible sobre el efecto de la presencia de música durante el ejercicio estructurado en la motivación, la vitalidad, la respuesta afectiva al ejercicio y la percepción subjetiva de esfuerzo, entre otros factores psicológicos, en los practicantes habituales de ejercicio. Métodos: La búsqueda de artículos publicados hasta Enero de 2018 se realizó en 3 bases de datos (Pubmed, PsycINFO y SPORTDiscus), siguiendo el modelo PICO, y se complementó manualmente. La siguiente información se extrajo de los artículos seleccionados: tipo de estudio, características de la intervención, música (condición e instrumentos), outcomes (e instrumentos de evaluación), resultados principales y calidad metodológica del estudio. El último se evaluó con la Quality Assessment Tool for Quantitative Studies. Resultados: Se han incluido 27 artículos, de los cuales 4 informaron efectos sobre la motivación, 11 sobre la respuesta afectiva al ejercicio, 22 sobre el esfuerzo percibido y 5 sobre los aspectos motivacionales de la música. La presencia de música se asoció positivamente con niveles más altos de motivación $(n=3$ de 4$)$, una respuesta afectiva aparentemente más positiva al ejercicio ( $\mathrm{n}=6$ de 11), pero en general no se asoció con niveles más bajos de esfuerzo percibido $(n=14$ de 22). Conclusión: Aunque la presencia de música parece tener un efecto potencialmente positivo sobre los niveles de motivación y la respuesta afectiva al ejercicio, la variabilidad en las características de la muestra, los protocolos de investigación y de los instrumentos de evaluación imposibilitan la retirada de conclusiones, enfatizando la necesidad de nuevos estudios sobre este tema.

Palabras clave: Música, ejercicio, motivación, afecto, percepción de esfuerzo.
\end{abstract}

ABSTRACT (150 words) (same order that title)

Aim: This systematic review sought to summarize the available evidence on the effect of music presence during structured exercise in motivation, vitality, exercise affective response, and perceived exertion, among other psychological factors, in regular exercisers. Methods: The search of articles published until January 2018 was conducted in three online databases (Pubmed, PsycINFO and SPORTDiscus) following PICO model, and complemented manually. The following information was extracted from the selected articles: type of study, intervention characteristics, music condition and instruments, outcomes and assessment instruments, main results, and study methodological quality. The later was assessed with the Quality Assessment Tool for Quantitative Studies. Results: A total of 27 articles were included, of which 4 reported effects on motivation, 11 on exercise affective response, 22 on perceived exertion, and 5 on the motivational aspects of music. Music presence was positively associated with higher levels of motivation ( $n=3$ of 4), an apparently more positive affective response to exercise ( $n=6$ of 11), but generally not associated with lower levels of perceived exertion $(n=14$ of 22). Conclusion: Although music presence appears to have a potentially positive effect on motivation levels and exercise affective response, the variability in sample characteristics, research protocols, and assessment instruments prevents drawing conclusions, highlighting the need for more studies on this topic.

Keywords: Music, exercise, motivation, affect, perceived exertion.

\section{INTRODUÇÃO}

Os benefícios físicos e psicológicos da prática de exercício regular estão bem documentados na literatura (Garber et al., 2011; World Health Organization, 2010; Pedersen \& Saltin, 2015; MiguelCalvo, Gallo, Mozas-Majano \& Hernández-López, 2011). No entanto, uma elevada proporção da população não cumpre as doses recomendadas de atividade física/exercício (Eurobarometer, 2017). Uma das razões mais comummente reportadas para a prática insuficiente de exercício/atividade física passa pela falta de motivação e interesse em ser fisicamente ativo (Eurobarometer, 2017). Sendo assim, é importante perceber que condições e/ou fatores ligados a esta prática poderão contribuir para uma adesão mais duradoura e consequentes benefícios. 


\section{Marques \& Carraça}

A motivação que energiza, dirige, ativa e mantém os nossos comportamentos (Ryan \& Deci, 2017) é um fator fundamental para se conseguir adoptar de forma sustentada a prática de exercício (Teixeira et al., 2012), aliada a maior bem-estar psicológico (Ryan \& Deci, 2017), principalmente a motivação que advém de fontes mais internas, ligadas àquilo que entendemos como importante ou que apreciamos (motivações autónomas) por oposição àquelas que advêm de fontes de pressão externas ou autoimpostas (Concha-Viera, Cuevas-Ferrer, Campos-Romero \& GonzálezHernández, 2017; Moreno \& Martínez, 2006). O efeito ergogénico do exercício, intimamente associado à resposta afetiva ao exercício, perceção subjetiva de esforço e vitalidade/energia que experienciamos durante e após o exercício, também parece ser decisivo na prática continuada de exercício (Rhodes \& Kates, 2015). Identificar formas de potenciar estes benefícios do exercício poderá contribuir para a adesão e manutenção da prática regular de exercício/atividade física ao longo da vida.

A música pode ser um fator chave na prática de exercício/atividade física a longo prazo, dado que pode gerar maiores e melhores níveis de motivação, bem como ser um recurso ergogénico capaz de influenciar positivamente o nosso rendimento durante a tarefa (Bigliassi, Estanislau, Carneiro, Dias \& Altimari, 2013; Karageorghis \& Terry, 1997). Além disso, pode aumentar os estados de humor e afetos positivos, distrair da monotonia (repetição exaustiva de movimentos) ou do esforço e das sensações de cansaço, fadiga e dor relacionadas com um determinado exercício (Souza \& Silva, 2010). A música também é capaz de alterar o nosso estado de espírito, de nos trazer memórias, de gerar emoções, de criar e aumentar a excitação e de reduzir inibições (Thakare, Mehrotra \& Singh, 2017). Se estes benefícios psicológicos forem confirmados de forma consistente na literatura, a presença de música durante a prática de exercício (aulas de grupo, programas de exercício estruturado) pode revelar-se um importante facilitador da prática regular e duradoura de atividade física, com o consequente impacto na melhoria da saúde e do estilo de vida da população.

O estudo dos efeitos da música durante o exercício é recente, mas tem vindo a despertar maior interesse da comunidade científica nos últimos tempos. A maior parte dos artigos existentes centra-se nos benefícios da utilização de música a nível físico, como a possibilidade de aumento da intensidade de uma atividade e da sua duração até à exaustão (Atan, 2013). Por outro lado, a literatura que analisa o seu impacto em variáveis de teor psicológico parece ser mais escassa. Deste modo, torna-se importante compilar essa evidência, no sentido de informar futuras iniciativas e intervenções de promoção de uma adesão sustentada à atividade física.

Esta revisão sistemática pretende assim sumariar a evidência científica que tenha investigado o efeito da utilização de música durante a prática de exercício físico estruturado em variáveis psicológicas como a motivação, a vitalidade, a resposta afetiva ao esforço e perceção subjetiva de esforço, e outras relacionadas.

\section{MÉTODOS}

Esta revisão sistemática foi realizada de acordo com o PRISMA (Preferred Reporting Items for Systematic Reviews and Meta-Analyses; Liberati et al., 2009). Teve um carácter integrador, baseando-se na agregação de resultados de estudos empíricos quantitativos, publicados em revistas com revisão de pares (Fernández-Ríos \& Buela-Casal, 2009).

\section{Critérios de elegibilidade}

Para serem incluídos nesta revisão, os estudos tinham de estar publicados em inglês, em revistas científicas com revisão de pares, ter amostras de adultos (entre os 18 e os 65 anos) praticantes regulares de exercício estruturado (i.e., aulas de grupo, programas de exercício) ou não estruturado, desde que sem qualquer doença psicológica diagnosticada. A exploração das associações da presença de música durante a realização de exercício estruturado com pelo menos uma das variáveis dependentes (motivação, vitalidade, resposta afetiva ao exercício e perceção subjetiva de esforço), ou outras relacionadas, foi considerada um critério de inclusão, independentemente do desenho de estudo. Não foram colocados critérios ao nível da intensidade ou tipologia do exercício. No caso de estudos de intervenção, não se colocaram critérios em relação ao grupo de controlo/comparação. Estudos de revisão, protocolos, comentários, artigos de opinião, teses/dissertações, estudos qualitativos e estudos de caso foram excluídos. 


\section{Efeitos psicológicos da música em praticantes de exercício}

\section{Estratégia de pesquisa e seleção de estudos}

A fase de pesquisa de artigos científicos com revisão de pares, publicados até Janeiro de 2018 ou em fase de impressão, decorreu entre 27 de janeiro e 17 de fevereiro de 2018. Foi realizada em três bases de dados eletrónicas: SPORTdiscus, Pubmed e PsycINFO.

A pesquisa incluiu a combinação de vários grupos de termos, de acordo com a estratégia PICO: 1) para a população/amostra abrangida: adult exercisers; 2) referente à intervenção/variável independente: Music OR rhythm OR sound OR music beat OR music tempo OR music speed OR music style OR melody OR music tune; 3 ) variáveis dependentes (outcomes): Motivation OR motives OR reasons OR regulations OR basic psychological needs OR psychological well-being OR well being OR affect OR mood OR emotion OR affective response $\mathrm{OR}$ emotional response $\mathrm{OR}$ vitality $\mathrm{OR}$ energy $\mathrm{OR}$ vigor $\mathrm{OR}$ fatigue $\mathrm{OR}$ perceived exertion OR effort.

Após a fase de pesquisa, a seleção dos estudos relevantes iniciou-se com a leitura dos títulos e resumos. Os artigos potencialmente relevantes foram guardados para uma leitura integral posterior. Após esta fase, os artigos que cumpriam os critérios de inclusão na íntegra foram escolhidos para integrar esta revisão sistemática de literatura. A seleção dos artigos foi feita por duas pessoas.

\section{Extração de dados e análise de informação}

Da leitura e análise dos artigos selecionados foram extraídas para uma tabela as seguintes informações de cada um deles: autores e ano (referência), amostra (idade, género), desenho de estudo, características da intervenção realizada, variável independente (música, condição e instrumentos se utilizados), variáveis dependentes e respetivos instrumentos de medida e resultados principais nas variáveis dependentes. Esta informação é apresentada na Tabela 1, estando os artigos organizados por ordem alfabética.

Relativamente aos resultados, começou-se por fazer uma breve caracterização dos estudos incluídos, seguida de uma apresentação descritiva e integradora dos resultados principais, organizada por variável dependente.

\section{Avaliação da qualidade metodológica dos estudos}

A qualidade metodológica foi avaliada com o Quality Assessment Tool for Quantitative Studies, desenvolvido no âmbito do Effective Public Health Practice Project (Thomas, Ciliska, Dobbins \& Micucci, 2004). A classificação final da qualidade dos estudos obteve-se através da atribuição de subclassificações (forte, moderado ou fraco) a um conjunto de 6 tópicos: Representatividade da amostra, desenho de estudo, fatores confundentes, blinding, recolha de dados e Retenção/dropouts. Uma classificação global foi determinada com base nas subclassificações atribuídas: forte se não houve subclassificações fracas; moderada se houve uma subclassificação fraca; fraca se houve mais de duas subclassificações fracas.

\section{RESULTADOS}

A pesquisa efetuada resultou na identificação de 337 artigos, após exclusão de 11 duplicados. Após leitura dos títulos e resumos, 52 artigos foram considerados potencialmente relevantes. Após leitura integral destes 52 artigos, 25 foram excluídos por não cumprirem um ou mais critérios de inclusão. Foram assim incluídos 27 artigos nesta revisão sistemática de literatura (Bood, Nijssen, Van der Kamp \& Roerdink, 2013; Brownley, McMurray \& Hackney, 1995; Crust, 2008; Edworthy \& Waring, 2006; Gabana, Van Raalte, Hutchinson, Brewer \& Pettipas, 2015; Guerrero, Fajardo \& Corona, 2017; Guillén \& Ruiz-Alfonso, 2015; Halfmann \& Smith, 2014; Hutchinson \& Karageorghis, 2013; Hutchinson, Karageorghis \& Jones, 2015; Jarraya et al., 2012; Karageorghis \& Jones, 2014; Karageorghis et al., 2009; Karageorghis et al., 2010; Lim, Atkinson, Karageorghis \& Eubank, 2009; Lim, Karageorghis, Romer \& Bishop, 2014; Lima-Silva et al., 2012; Lopes-Silva, Lima-Silva, Bertuzzi \& Silva-Cavalcante, 2015; Macone, Baldari, Zelli \& Guidetti, 2006; Mohammadzadeh, Tartibiyan \& Ahmadi, 2008; Nakamura, Pereira, Papini, Nakamura \& Kokubun, 2010; Sanchez, Moss, Twist \& Karageorghis, 2014; Shaulov \& Lufi, 2009; Stork, Kwan, Gibala \& Martin Ginis, 2014; Szmedra \& Bacharach, 1998; Tiev, Manire, Robertson \& Barbara, 2010; Young, Sands \& Jung, 2009) (Figura 1). 


\section{Marques \& Carraça}
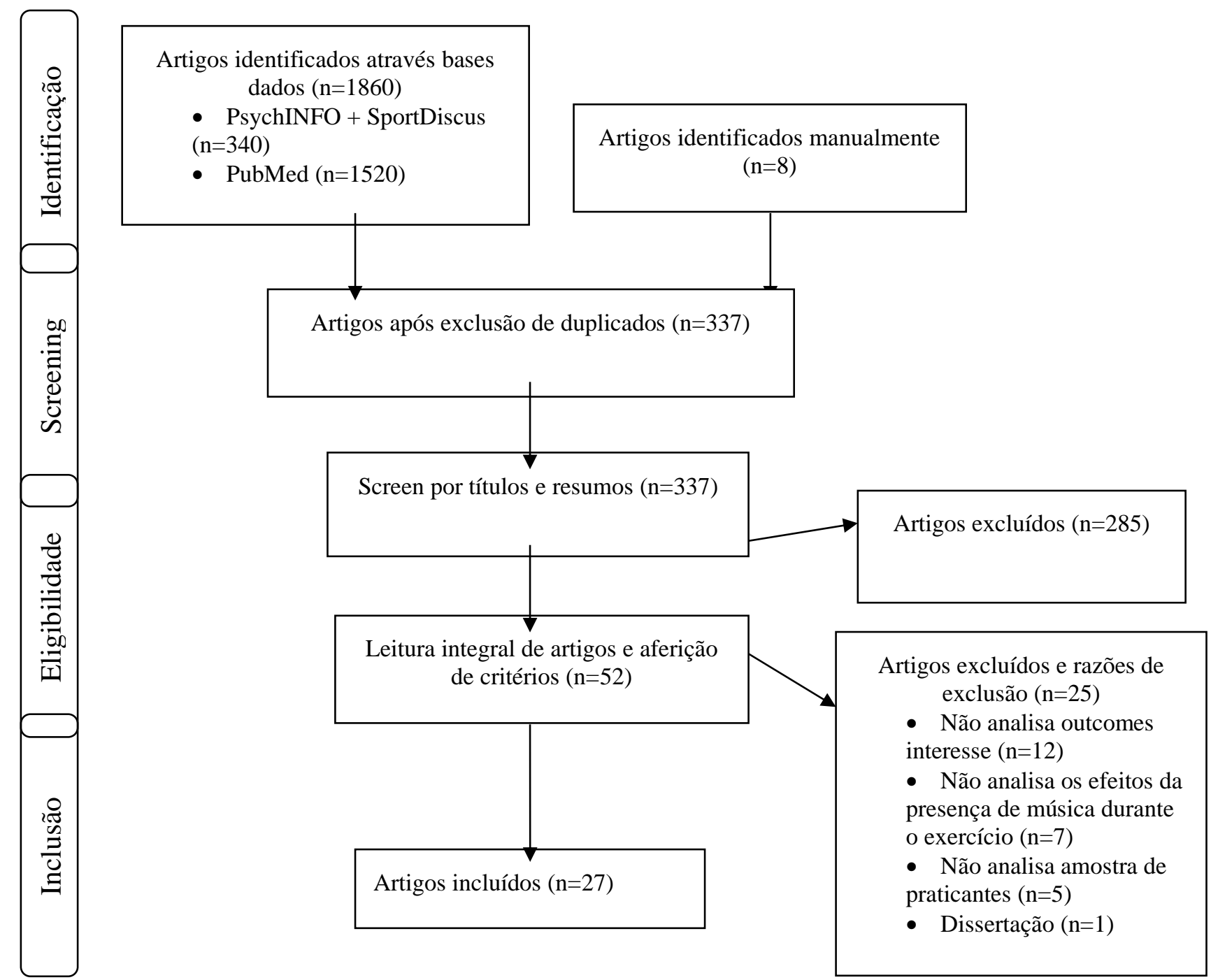

Figura 1: Fluxograma

\section{Características dos estudos incluídos}

Dos 27 artigos incluídos, 25 foram publicados entre 2000 e a atualidade, sendo os outros 2 da última década do século XX. Já no que diz respeito à amostra, 1 estudo incluiu uma amostra unicamente feminina, 7 artigos incluíram uma amostra masculina e os restantes 19 incluíram uma amostra mista. Quatro dos artigos incluíram indivíduos com idade superior a 30 anos, mas os restantes 23 incluíram amostras com idades inferiores a 30 anos. No que respeita ao tipo de estudo, incluiu-se 1 estudo transversal e 26 estudos experimentais.

Relativamente às variáveis analisadas e aos instrumentos de avaliação, 20 estudos mediram a 


\section{Efeitos psicológicos da música em praticantes de exercício}

perceção subjetiva de esforço (RPE), maioritariamente através da Escala de Borg de 6-20 (n=13) ou de 0-10 $(n=6)$. A resposta afetiva ao esforço foi avaliada em 12 artigos, principalmente através da Feeling Scale $(\mathrm{n}=9)$. A motivação (quantidade) foi avaliada através da Escala de Tenenbaum $(n=3)$. Apenas um estudo avaliou um dos tipos/qualidades da motivação, através do Intrinsic Motivation Inventory. Não foram utilizados outros instrumentos para avaliar os outros tipos/qualidades de motivação em nenhum dos artigos incluídos. $\mathrm{O}$ prazer/diversão, constructo muito próximo da motivação intrínseca, foi avaliado por 2 vezes, com diferentes instrumentos. Algumas variáveis foram avaliadas apenas uma vez (por exemplo, o humor e a ansiedade), e alguns instrumentos foram utilizados apenas uma vez (por exemplo, Exercise Induced Feeling Inventory). A Vitalidade não foi avaliada em nenhum dos artigos. As componentes motivacionais da música foram avaliadas através do Brunel Music Rating Inventory-I $(n=1)$ e do Brunel Music Rating Inventory-2 $(n=4)$.

\section{Qualidade metodológica}

No que se refere à qualidade metodológica dos estudos, 18 foram classificados com qualidade moderada (Bood et al., 2013; Gabana et al., 2015; Guillén \& Ruiz-Alfonso, 2015; Halfmann \& Smith, 2014; Hutchinson \& Karageorghis, 2013; Hutchinson, Karageorghis \& Jones, 2015; Jarraya et al., 2012; Karageorghis \& Jones, 2014; Karageorghis et al., 2009; Karageorghis et al., 2010; Lim et al., 2009; Lim et al., 2014; Lopes-Silva et al., 2015; Macone et al., 2006; Nakamura et al., 2010; Sanchez et al., 2014; Stork et al., 2014; Tiev et al., 2010) e 9 com qualidade fraca (Brownley, McMurray \& Hackney, 1995; Crust, 2008; Edworthy \& Waring, 2006; Guerrero, Fajardo \& Corona, 2017; Lima-Silva et al. 2012; Mohammadzadeh, Tartibiyan \& Ahmadi, 2008; Shaulov \& Lufi, 2009; Szmedra \& Bacharach, 1998; Young, Sands \& Jung, 2009). Esta avaliação derivou do facto das amostras dos vários estudos serem compostas por voluntários ou formadas por conveniência, não sendo representativas da população em nenhum dos casos (sub-classificação de representatividade da amostra fraca), e ainda do facto de não ter sido assegurado que os responsáveis pelas avaliações feitas estivessem cegos no que respeita à condição dos participantes.

\section{Resultados principais}

Nesta revisão sistemática pretendeu-se analisar os efeitos da presença de música durante a prática de exercício na motivação, resposta afetiva ao esforço, vitalidade, perceção subjetiva de esforço, entre outras variáveis psicológicas.

Motivação. Um total de 4 estudos analisaram os efeitos da presença de música durante o exercício na quantidade da motivação. Destes, 3 estudos mostraram que a presença de música elevava os níveis de motivação, sobretudo quando a música era considerada motivadora (Gabana et al., 2015; Hutchinson \& Karageorghis, 2013; Hutchinson, Karageorghis \& Jones, 2015), enquanto 1 estudo não revelou efeitos da presença da música (Stork et al., 2014).

Apenas um estudo avaliou o efeito da presença de música na qualidade da motivação, nomeadamente na motivação intrínseca, não tendo sido observados efeitos significativos na condição com música (Karageorghis \& Jones, 2014). Porém, 3 estudos que investigaram os efeitos da música no prazer/diversão associado à prática de exercício (um indicador de motivação intrínseca) mostraram que este foi superior na presença de música (Shaulov \& Lufi, 2009; Stork et al., 2014; Tiev et al., 2010). Não se encontraram artigos que analisassem os efeitos da música nos restantes tipos motivação (extrínseca) e na amotivação para o exercício. Ou seja, não foi encontrado nenhum estudo que avaliasse a qualidade da motivação na sua plenitude.

Resposta afetiva ao esforço. As respostas afetivas foram significativamente mais positivas na presença de música em 6 estudos (Edworthy \& Waring, 2006; Hutchinson \& Karageorghis, 2013; Hutchinson, Karageorghis \& Jones, 2015; Karageorghis \& Jones, 2014; Karageorghis et al., 2009; Lim et al., 2014), não se tendo encontrado diferenças significativas em 4 estudos (Karageorghis et al., 2010; Lim et al., 2009; Sanchez et al., 2014; Stork et al., 2014). Alguns estudos sugeriram ainda que certas características podem moderar os efeitos da presença de música na resposta afetiva, designadamente o género, a qualidade motivadora da música e a presença de vídeo. A presença de música parece beneficiar a resposta afetiva ao esforço nas mulheres (Karageorghis et al., 2010), nas pessoas menos treinadas (Brownley, 


\section{Marques \& Carraça}

McMurray \& Hackney, 1995), quando a música é considerada motivadora (Karageorghis et al., 2009; Hutchinson \& Karageorghis, 2013) ou quando é acompanhada de vídeo (Hutchinson, Karageorghis \& Jones, 2015).

Analisando a qualidade dos estudos e os resultados obtidos, não se considera que esta tenha interferido, uma vez que os 4 artigos em que não se observaram efeitos da presença de música foram avaliados como tendo uma qualidade moderada, bem como 5 daqueles em que se encontraram efeitos.

Perceção subjetiva de esforço. Cinco dos artigos analisados mostraram níveis significativamente menores de perceção de esforço na presença de música (Bood et al., 2013; Hutchinson, Karageorghis \& Jones, 2015; Mohammadzadeh, Tartibiyan \& Ahmadi, 2008; Szmedra \& Bacharach, 1998; Tiev et al., 2010), mas os restantes 14 não encontraram diferenças significativas entre condições (Brownley, McMurray \& Hackney, 1995; Edworthy \& Waring, 2006; Gabana et al., 2015; Guerrero, Fajardo \& Corona, 2017; Guillén \& Ruiz-Alfonso, 2015; Halfmann \& Smith, 2014; Jarraya et al., 2012; Karageorghis et al., 2009; Lim et al., 2009; Lim et al., 2014; Lima-Silva et al., 2012; Lopes-Silva et al., 2015; Sanchez et al., 2014; Stork et al., 2014; Szmedra \& Bacharach, 1998; Tiev et al., 2010; Young, Sands \& Jung, 2009). Algumas características parecem moderar os efeitos da presença de música na perceção subjetiva de esforço, nomeadamente a presença simultânea de vídeos que potencia ainda mais a redução da percepção de esforço (Hutchinson, Karageorghis \& Jones, 2015) ou o facto da música não ser apreciada, o que pelo contrário, elimina os efeitos positivos da presença de música, elevando a perceção subjetiva de esforço (Nakamura et al., 2010).

Dos 14 artigos em que não foram encontradas diferenças significativas, 9 foram qualificados com uma qualidade moderada e 5 com fraca, enquanto que dos 5 estudos em que houve diferenças significativas, apenas 2 foram avaliados com qualidade fraca. Neste sentido, parece-nos que a qualidade dos estudos não deverá ter interferido nos resultados.

Vitalidade. Não foram encontrados estudos que explorassem os efeitos da presença de música durante o exercício na vitalidade.

Outras variáveis psicológicas relacionadas. A pesquisa efetuada revelou a existência de efeitos positivos da presença de música em outras variáveis psicológicas relacionadas, apesar de cada variável ter sido analisada em um ou dois estudos apenas. Resumindo os resultados encontrados, verificaram-se diminuições significativas da tensão, depressão, confusão e estado de ansiedade (Macone et al., 2006), maiores níveis de envolvimento e absorção no exercício (i.e., flow) e de motivação intrínseca (Karageorghis \& Jones, 2014), e ainda maiores níveis de excitação/arousal (Lim et al., 2014). Verificou-se ainda que a velocidade da música e o género poderão ser fatores moderadores destes efeitos positivos da música (Karageorghis \& Jones, 2014).

Relação entre as componentes da música e a motivação. Cinco estudos tentaram averiguar se diferentes características da música geram níveis de motivação diferentes nos sujeitos. O ritmo, a velocidade/tempo e a batida da música estão entre as características musicais consideradas mais motivadoras (Crust, 2008; Guillén \& Ruiz-Alfonso, 2015; Lim et al., 2009). Outras características como a melodia, o estilo musical, as associações pessoais e o conteúdo emocional, parecem ser capazes de intensificar os afetos positivos dos praticantes de exercício (Lim et al., 2009). As mulheres parecem valorizar mais a melodia da música, enquanto os homens atribuem maior importância à associação da música ao desporto; porém, apenas um estudo de qualidade fraca comparou os géneros (Crust, 2008). Dois estudos não encontraram efeitos distintos das várias componentes da música (Lopes-Silva et al., 2015; Stork et al., 2014). 


\section{Efeitos psicológicos da música em praticantes de exercício}

Tabela 1. Características dos estudos incluídos.

\begin{tabular}{|c|c|c|c|c|c|c|}
\hline Estudo & Amostra & $\begin{array}{l}\text { Tipo de Estudo e } \\
\text { Intervenção }\end{array}$ & $\begin{array}{l}\text { Efeito Música } \\
\text { (instrumentos) }\end{array}$ & $\begin{array}{c}\text { Outcomes } \\
\text { (instrumentos) }\end{array}$ & Resultados & $\begin{array}{c}\text { Qualidade } \\
\text { Metodológica }\end{array}$ \\
\hline $\begin{array}{l}\text { Bood, } \\
\text { Nijssen, } \\
\text { van der Kamp e } \\
\text { Roerdink (2013) }\end{array}$ & $\begin{array}{l}19 \text { corredores } \\
\text { recreativos } \\
(9 \text { mulheres; } 19- \\
27 \text { anos })\end{array}$ & $\begin{array}{l}\text { Estudo } \\
\text { Experimental: } \\
\text { correr até à exaustão } \\
\text { sob } 3 \text { condições: } \\
\text { - controlo } \\
\text { - metrónomo } \\
\text { (sincronizado com o } \\
\text { passo) } \\
\text { - com música } \\
\text { motivadora }\end{array}$ & $\begin{array}{l}\text { Condições } \\
\text { experimentais } \\
\text { diferentes }\end{array}$ & $\begin{array}{l}\text { Perceção de } \\
\text { Esforço (Escala de } \\
\text { Borg, 6-20) }\end{array}$ & $\begin{array}{l}\text { A perceção de esforço foi } \\
\text { significativamente menor na condição com } \\
\text { música do que no controlo. }\end{array}$ & Moderado \\
\hline $\begin{array}{l}\text { Brownley, } \\
\text { McMurray } \\
\text { e Hackney } \\
\text { (1995) }\end{array}$ & $\begin{array}{l}\text { 16 voluntários } \\
\text { (12 mulheres; } \\
19-28 \text { anos) } \\
\text { divididos em } 2 \\
\text { grupos: } \\
\text {-Treinados; } \\
\text {-Não treinados }\end{array}$ & $\begin{array}{l}\text { Estudo } \\
\text { Experimental: } \\
\text { andar/correr } 30 \mathrm{~min}, \\
\text { intensidade } \\
\text { crescente, } \\
\text { sob } 3 \text { condições: } \\
\text { - sem música, } \\
\text { - música relaxante } \\
\text { (igual para os dois } \\
\text { grupos) } \\
\text { - música rápida } \\
\text { (opção do grupo) }\end{array}$ & $\begin{array}{l}\text { Condições } \\
\text { experimentais } \\
\text { diferentes }\end{array}$ & $\begin{array}{l}\text { Perceção de } \\
\text { Esforço (Escala de } \\
\text { Borg, 6-20) } \\
\text { Afetos (Feeling } \\
\text { Scale) }\end{array}$ & $\begin{array}{l}\text { Não se verificaram diferenças significativas } \\
\text { na perceção de esforço. Na condição com } \\
\text { música, sujeitos não treinados reportaram } \\
\text { afetos mais positivos com música rápida, a } \\
\text { intensidades baixa e alta, enquanto os } \\
\text { treinados reportaram menos afetos positivos } \\
\text { com música rápida, independentemente da } \\
\text { intensidade do exercício. Na condição sem } \\
\text { música, não se verificaram diferenças } \\
\text { significativas nos afetos. }\end{array}$ & Fraco \\
\hline Crust (2008) & $\begin{array}{l}55 \text { adultos: } \\
24 \text { homens } \\
(38.8 \pm 11.8 \\
\text { anos }) \text { e } \\
31 \text { mulheres } \\
(32.4 \pm 9.6 \text { anos }) \\
\text { praticantes de } \\
\text { exercício }\end{array}$ & $\begin{array}{l}\text { Estudo Transversal: } \\
\text { Avaliação dos } \\
\text { efeitos da música } \\
\text { após um treino em } \\
\text { circuito com música }\end{array}$ & $\begin{array}{l}\text { Brunel Music } \\
\text { Rating Inventory } \\
2\end{array}$ & $\begin{array}{l}\text { Reação Emocional } \\
\text { (Affect Intensity } \\
\text { Measure) }\end{array}$ & $\begin{array}{l}\text { A intensidade do afeto mostrou-se } \\
\text { positivamente associada à melodia, estilo } \\
\text { musical, conteúdo lírico, associações } \\
\text { pessoais e conteúdo emocional. } \\
\text { A velocidade, a batida e o ritmo da música } \\
\text { foram as características consideradas mais } \\
\text { motivadoras durante o exercício. } \\
\text { Para as mulheres a melodia da música é } \\
\text { significativamente mais motivadora durante } \\
\text { o exercício, enquanto os homens } \\
\text { consideram que quando há uma associação } \\
\text { da música com o desporto, ela é mais } \\
\text { motivadora. }\end{array}$ & Fraco \\
\hline
\end{tabular}




\section{Marques \& Carraça}

\begin{tabular}{|c|c|c|c|c|c|c|}
\hline $\begin{array}{l}\text { Edworthy e Waring } \\
\text { (2006) }\end{array}$ & $\begin{array}{l}30 \text { adultos } \\
(15 \text { mulheres; } \\
18-63 \text { anos }) \\
\text { praticantes de } \\
\text { exercício }\end{array}$ & $\begin{array}{l}\text { Estudo } \\
\text { Experimental: } \\
\text { sessões de } 10 \\
\text { minutos em } \\
\text { passadeira, sob } 5 \\
\text { condições: } \\
\text { - sem música } \\
\text { - música lenta a } 60 \\
\text { dB } \\
\text { - música lenta a } 80 \\
\text { dB } \\
\text { - música rápida a } 60 \\
\text { dB } \\
\text { - música rápida a } 80 \\
\text { dB }\end{array}$ & $\begin{array}{l}\text { Condições } \\
\text { experimentais } \\
\text { diferentes }\end{array}$ & $\begin{array}{l}\text { Perceção de } \\
\text { Esforço (Escala de } \\
\text { Borg, 6-20) } \\
\text { Afetos (Feeling } \\
\text { Scale) }\end{array}$ & $\begin{array}{l}\text { A perceção de esforço não teve diferenças } \\
\text { significativas entre as condições. Os afetos } \\
\text { foram significativamente mais positivos em } \\
\text { todas as condições com música. }\end{array}$ & Fraco \\
\hline $\begin{array}{l}\text { Gabana, } \\
\text { Van Raalte, } \\
\text { Hutchinson, Brewer } \\
\text { e Pettipas (2015) }\end{array}$ & $\begin{array}{l}26 \text { mulheres } \\
\text { praticantes de } \\
\text { remo } \\
(19.31 \pm 1.26 \\
\text { anos })\end{array}$ & $\begin{array}{l}\text { Estudo } \\
\text { Experimental: } \\
\text { 1000m de } \\
\text { remo/canoagem a } \\
\text { máxima velocidade } \\
\text { (4 condições para } \\
\text { todos): } \\
\text { - controlo } \\
\text { - com música (tema } \\
\text { escolhido pela } \\
\text { equipa) } \\
\text { - com treinador } \\
\text { - com música e } \\
\text { treinador }\end{array}$ & $\begin{array}{l}\text { Condições } \\
\text { experimentais } \\
\text { diferentes }\end{array}$ & $\begin{array}{l}\text { Perceção de } \\
\text { Esforço (Escala de } \\
\text { Borg, 0-10) } \\
\text { Motivação } \\
\text { (escala de } \\
\text { Tenenbaum) }\end{array}$ & $\begin{array}{l}\text { Não houve diferenças significativas na } \\
\text { perceção de esforço entre as condições (com } \\
\text { ou sem presença de música e com ou sem } \\
\text { treinador). A motivação foi } \\
\text { significativamente maior nas condições com } \\
\text { música do que no grupo de controlo. }\end{array}$ & Moderado \\
\hline $\begin{array}{l}\text { Guerrero, Fajardo e } \\
\text { Corona (2017) }\end{array}$ & $\begin{array}{l}11 \text { alunos } \\
\text { fisicamente } \\
\text { ativos: } \\
8 \text { homens } \\
(21.2 \pm 2.1 \text { anos }) \mathrm{e} \\
3 \text { mulheres } \\
(20.7 \pm 0.6 \text { anos })\end{array}$ & $\begin{array}{l}\text { Estudo } \\
\text { Experimental: } \\
30 \text { minutos de } \\
\text { atividade física } \\
\text { contínua, sob } 3 \\
\text { condições: } \\
\text { - sem música } \\
\text { - música a } 65 \mathrm{~dB} \\
\text { - música a } 95 \mathrm{~dB}\end{array}$ & $\begin{array}{l}\text { Condições } \\
\text { experimentais } \\
\text { diferentes }\end{array}$ & $\begin{array}{l}\text { Perceção de } \\
\text { Esforço (Escala de } \\
\text { Borg, 0-10) }\end{array}$ & $\begin{array}{l}\text { Não houve diferenças significativas na } \\
\text { perceção de esforço entre as condições. }\end{array}$ & Fraco \\
\hline
\end{tabular}




\section{Efeitos psicológicos da música em praticantes de exercício}

\begin{tabular}{|c|c|c|c|c|c|c|}
\hline $\begin{array}{l}\text { Guillén e } \\
\text { Ruiz-Alfonso } \\
\text { (2015) }\end{array}$ & $\begin{array}{l}24 \text { atletas } \\
\text { ( } 7 \text { mulheres; } \\
30.7 \pm 10.3 \text { anos) }\end{array}$ & $\begin{array}{l}\text { Estudo } \\
\text { Experimental: } \\
\text { pedalar máxima } \\
\text { distância durante } 20 \\
\text { minutos: } \\
\text { - sem música } \\
\text { - com música tecno } \\
\text { - com música } \\
\text { clássica }\end{array}$ & $\begin{array}{l}\text { Brunel Music } \\
\text { Rating Inventory } \\
\text { I }\end{array}$ & $\begin{array}{l}\text { Perceção de } \\
\text { Esforço (Escala de } \\
\text { Borg, 6-20) }\end{array}$ & $\begin{array}{l}\text { Não houve diferenças significativas na } \\
\text { perceção de esforço entre as várias } \\
\text { condições. Houve diferenças significativas } \\
\text { em } 9 \text { das } 13 \text { componentes motivacionais das } \\
\text { músicas, tendo estas sido superiores na } \\
\text { condição de música clássica: familiaridade, } \\
\text { tempo, ritmo, associação da música com o } \\
\text { desporto, sucesso da música, associação da } \\
\text { música com um filme ou um vídeo, } \\
\text { harmonia e qualidade da música } \\
\text { estimulante. }\end{array}$ & Moderado \\
\hline $\begin{array}{l}\text { Halfmann e Smith } \\
\text { (2014) }\end{array}$ & $\begin{array}{l}17 \text { praticantes de } \\
\text { exercício: } \\
8 \text { homens } \\
(18.3 \pm 0.5 \text { anos }) \\
\text { e } 9 \text { mulheres } \\
(18.9 \pm 0.9 \text { anos })\end{array}$ & $\begin{array}{l}\text { Estudo } \\
\text { Experimental: } \\
\text { completar 5km em } \\
\text { bicicleta } \\
\text { estacionária, } 2 \\
\text { condições: } \\
\text { - sem música } \\
\text { - com música } \\
\text { ambiente de } 140 \mathrm{bpm}\end{array}$ & $\begin{array}{l}\text { Condições } \\
\text { experimentais } \\
\text { diferentes }\end{array}$ & $\begin{array}{l}\text { Perceção de } \\
\text { Esforço (Escala de } \\
\text { Borg, 6-20) }\end{array}$ & $\begin{array}{l}\text { Não houve diferenças significativas na } \\
\text { perceção de esforço entre as duas condições. }\end{array}$ & Moderado \\
\hline $\begin{array}{l}\text { Hutchinson e } \\
\text { Karageorghis } \\
\text { (2013) }\end{array}$ & $\begin{array}{l}34 \text { pessoas } \\
(12 \text { mulheres; } \\
19.20 \pm 4.9 \text { anos) } \\
\text { estudantes de } \\
\text { desporto (prática } \\
\text { regular de } \\
\text { exercício) }\end{array}$ & $\begin{array}{l}\text { Estudo Experimental } \\
7 \text { minutos de corrida } \\
\text { em passadeira, } 3 \\
\text { condições: } \\
\text { - sem música } \\
\text { - música não } \\
\text { motivadora } \\
\text { - música motivadora }\end{array}$ & $\begin{array}{l}\text { Condições } \\
\text { experimentais } \\
\text { diferentes }\end{array}$ & $\begin{array}{l}\text { Afetos (Feeling } \\
\text { Scale) } \\
\text { Motivação } \\
\text { (escala de } \\
\text { Tenenbaum) }\end{array}$ & $\begin{array}{l}\text { Os afetos foram mais positivos na condição } \\
\text { com música motivadora do que nas outras } \\
\text { duas. A motivação foi significativamente } \\
\text { maior na condição com música motivadora } \\
\text { face às outras duas. } \\
\text { A motivação foi também maior na condição } \\
\text { com música não motivadora face à condição } \\
\text { sem música. }\end{array}$ & Moderado \\
\hline $\begin{array}{l}\text { Hutchinson, } \\
\text { Karageorghis e } \\
\text { Jones (2015) }\end{array}$ & $\begin{array}{l}24 \text { pessoas } \\
\text { fisicamente ativas } \\
(10 \text { mulheres; } \\
21.3 \pm 3.9 \text { anos })\end{array}$ & $\begin{array}{l}\text { Estudo } \\
\text { Experimental: } \\
3 \text { condições: } \\
\text { - controlo } \\
\text { - música } \\
\text { - música e vídeo } \\
\text { x } 2 \text { intensidades: } \\
\text {-10\% acima do } \\
\text { limiar respiratório } \\
\text {-10\% abaixo do } \\
\text { limiar respiratório }\end{array}$ & $\begin{array}{l}\text { Condições } \\
\text { experimentais } \\
\text { diferentes }\end{array}$ & $\begin{array}{l}\text { Perceção de } \\
\text { Esforço (Escala de } \\
\text { Borg, 0-10) } \\
\text { Afetos (Feeling } \\
\text { Scale)Motivação } \\
\text { (Escala de } \\
\text { Tenenbaum) }\end{array}$ & $\begin{array}{l}\text { A perceção de esforço foi } \\
\text { significativamente menor no grupo com } \\
\text { vídeo e música do que no controlo. Os } \\
\text { afetos foram mais positivos no grupo com } \\
\text { música e vídeo, depois no de música e por } \\
\text { fim no controlo. Os afetos após o exercício } \\
\text { foram mais positivos nas condições } \\
\text { experimentais do que no controlo (na } \\
\text { intensidade mais baixa). Os níveis de } \\
\text { motivação foram significativamente maiores } \\
\text { nas condições experimentais do que no } \\
\text { controlo. }\end{array}$ & Moderado \\
\hline
\end{tabular}




\section{Marques \& Carraça}

\begin{tabular}{|c|c|c|c|c|c|c|}
\hline Jarraya, et al. (2012) & $\begin{array}{l}20 \text { homens atletas } \\
(20.6 \pm 1.8 \text { anos })\end{array}$ & $\begin{array}{l}\text { Estudo } \\
\text { Experimental: } \\
2 \text { sessões para todos } \\
\text { (Wingate Test) } \\
\text { - aquecimento com } \\
\text { música } \\
\text { - aquecimento sem } \\
\text { música }\end{array}$ & $\begin{array}{l}\text { Condições } \\
\text { experimentais } \\
\text { diferentes }\end{array}$ & $\begin{array}{l}\text { Perceção de } \\
\text { Esforço (Escala de } \\
\text { Borg, 6-20) }\end{array}$ & $\begin{array}{l}\text { Os efeitos da música e da interação música- } \\
\text { exercício na perceção de esforço não foram } \\
\text { significativos. }\end{array}$ & Moderado \\
\hline $\begin{array}{l}\text { Karageorghis e } \\
\text { Jones (2014) }\end{array}$ & $\begin{array}{l}22 \text { adultos: } \\
11 \text { homens } \\
(19.6 \pm 1.6 \text { anos) } \\
\text { e } \\
11 \text { mulheres } \\
(20.3 \pm 1.6 \text { anos) } \\
\text { estudantes de } \\
\text { desporto (prática } \\
\text { regular de } \\
\text { exercício) }\end{array}$ & $\begin{array}{l}\text { Estudo } \\
\text { Experimental: } \\
\text { exercício em } \\
\text { passadeira sob } 5 \\
\text { condições: } \\
\text { - controlo (sem } \\
\text { música) } \\
\text { - velocidade musical } \\
\text { lenta } \\
\text { - velocidade musical } \\
\text { média } \\
\text { - velocidade musical } \\
\text { rápida } \\
\text { - velocidade musical } \\
\text { muito rápida }\end{array}$ & $\begin{array}{l}\text { Condições } \\
\text { experimentais } \\
\text { diferentes }\end{array}$ & $\begin{array}{l}\text { Afetos (Feeling } \\
\text { Scale) } \\
\text { Motivação } \\
\text { (Escalas de } \\
\text { Interest-Enjoyment } \\
\text { e Pressure Tension, } \\
\text { do Intrinsic } \\
\text { Motivation } \\
\text { Inventory) } \\
\text { Envolvimento no } \\
\text { exercício } \\
\text { (Flow State Scale } \\
\text { 2) }\end{array}$ & $\begin{array}{l}\text { A resposta afetiva foi significativamente } \\
\text { mais positiva nas condições com música. A } \\
\text { análise por géneros indicou que os homens } \\
\text { apresentaram afetos menos positivos na } \\
\text { condição sem música a velocidade média, } \\
\text { rápida e muito rápida. Também } \\
\text { apresentaram afetos positivos menores com } \\
\text { música lenta do que com velocidade média. } \\
\text { Nas mulheres, na condição sem música, os } \\
\text { afetos positivos foram menores do que nas } \\
\text { condições com música; na música lenta } \\
\text { também foram menores do que na de } \\
\text { velocidade média. } \\
\text { Não se verificaram diferenças significativas } \\
\text { na motivação intrínseca entre condições. A } \\
\text { análise por géneros indicou que o nível de } \\
\text { motivação intrínseca nos homens foi menor } \\
\text { sem música do que com música a } \\
\text { velocidade média. Nas mulheres o nível de } \\
\text { motivação intrínseca foi menor sem música } \\
\text { quando comparado com as outras condições. } \\
\text { Com a música lenta, as mulheres } \\
\text { apresentaram níveis de motivação intrínseca } \\
\text { menores do que na música a velocidades } \\
\text { média e rápida. } \\
\text { Os níveis de interesse/diversão foram } \\
\text { menores na condição sem música do que } \\
\text { nas com música; menores na música lenta } \\
\text { comparando com as velocidades média e } \\
\text { rápida; maiores na música com velocidade } \\
\text { rápida quando comparada com a muito } \\
\text { rápida. Os níveis de pressão/tensão foram }\end{array}$ & Moderado \\
\hline
\end{tabular}




\section{Efeitos psicológicos da música em praticantes de exercício}

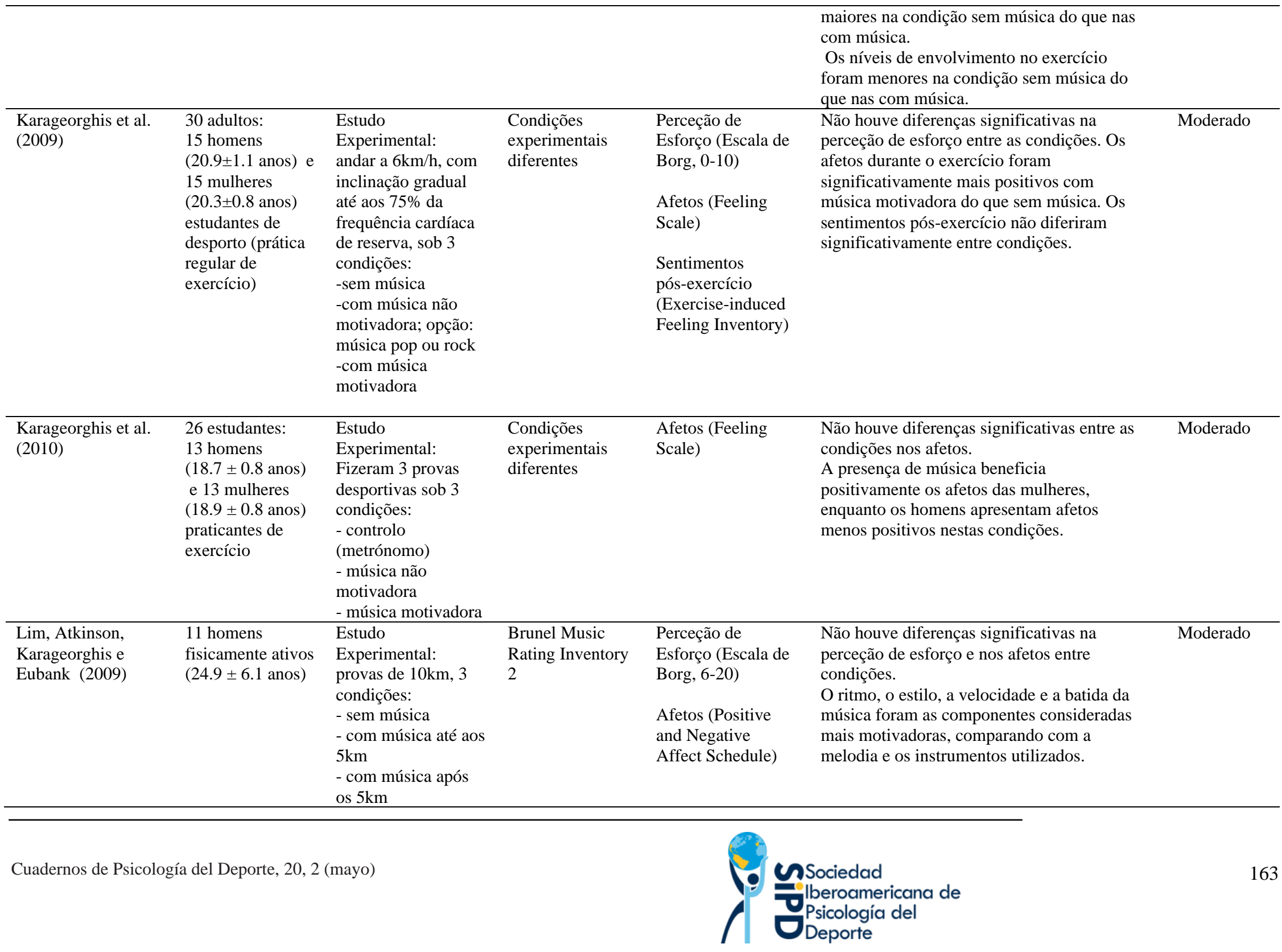




\section{Marques \& Carraça}

\begin{tabular}{|c|c|c|c|c|c|c|}
\hline $\begin{array}{l}\text { Lim, Karageorghis, } \\
\text { Romer e Bishop } \\
\text { (2014) }\end{array}$ & $\begin{array}{l}24 \text { homens } \\
\text { fisicamente ativos } \\
(22 \pm 4 \text { anos })\end{array}$ & $\begin{array}{l}\text { Estudo } \\
\text { Experimental: } \\
6 \text { minutos de } \\
\text { ciclismo em cada } \\
\text { condição: } \\
\text { - sem música, } \\
\text { controlo } \\
\text { - metrónomo } \\
\text { sincrónico (150 } \\
\text { bpm) } \\
\text { - música sincrónica } \\
\text { (150 bpm) } \\
\text { - música } \\
\text { assincrónica (170 } \\
\text { bpm) }\end{array}$ & $\begin{array}{l}\text { Condições } \\
\text { experimentais } \\
\text { diferentes }\end{array}$ & $\begin{array}{l}\text { Afetos (Feeling } \\
\text { Scale) } \\
\text { Excitação/ } \\
\text { Entusiasmo (Felt } \\
\text { Arousal Scale) }\end{array}$ & $\begin{array}{l}\text { Afetos mais positivos e níveis de excitação } \\
\text { maiores nas condições com música do que } \\
\text { com o metrónomo ou controlo. }\end{array}$ & Moderado \\
\hline $\begin{array}{l}\text { Lima-Silva et al. } \\
\text { (2012) }\end{array}$ & $\begin{array}{l}15 \text { homens } \\
\text { praticantes de } \\
\text { exercício } \\
(22.5 \pm 3.5 \text { anos })\end{array}$ & $\begin{array}{l}\text { Estudo } \\
\text { Experimental: } \\
5 \mathrm{~km} \text { a andar/correr, } \\
\text { sob } 3 \text { condições: } \\
\text { - sem música toda a } \\
\text { prova - música nos } \\
\text { primeiros } 1.5 \mathrm{~km} \\
\text { - música nos } 1.5 \mathrm{~km} \\
\text { finais }\end{array}$ & $\begin{array}{l}\text { Condições } \\
\text { experimentais } \\
\text { diferentes }\end{array}$ & $\begin{array}{l}\text { Perceção de } \\
\text { Esforço (Escala de } \\
\text { Borg, 6-20) }\end{array}$ & $\begin{array}{l}\text { Não houve diferenças significativas na } \\
\text { perceção de esforço entre condições. }\end{array}$ & Fraco \\
\hline $\begin{array}{l}\text { Lopes-Silva, Lima- } \\
\text { Silva, Bertuzzi e } \\
\text { Silva-Cavalcante } \\
\text { (2015) }\end{array}$ & $\begin{array}{l}14 \text { homens } \\
\text { fisicamente ativos } \\
(24.0 \pm 1.7 \text { anos })\end{array}$ & $\begin{array}{l}\text { Estudo } \\
\text { Experimental: } \\
\text { Pedalar até à } \\
\text { exaustão segundo as } \\
\text { condições: } \\
\text { - pré-fadiga + } \\
\text { música } \\
\text { - pré-fadiga + não } \\
\text { música } \\
\text { - música } \\
\text { - sem música e sem } \\
\text { pré-fadiga }\end{array}$ & $\begin{array}{l}\text { Brunel Music } \\
\text { Rating } \\
\text { Inventory-2 (logo } \\
\text { após a prova) }\end{array}$ & $\begin{array}{l}\text { Perceção de } \\
\text { Esforço (Escala de } \\
\text { Borg, 6-20) }\end{array}$ & $\begin{array}{l}\text { A perceção de esforço não apresentou } \\
\text { diferenças significativas consoante a } \\
\text { presença ou não de música. As várias } \\
\text { componentes da música foram consideradas } \\
\text { igualmente motivadoras. }\end{array}$ & Moderado \\
\hline $\begin{array}{l}\text { Macone, Baldari, } \\
\text { Zelli e Guidetti } \\
\text { (2006) }\end{array}$ & $\begin{array}{l}27 \text { sujeitos } \\
\text { praticantes de } \\
\text { exercício }\end{array}$ & $\begin{array}{l}\text { Estudo } \\
\text { Experimental: }\end{array}$ & $\begin{array}{l}\text { Condições } \\
\text { experimentais } \\
\text { diferentes }\end{array}$ & $\begin{array}{l}\text { Humor } \\
\text { (Profile of Mood } \\
\text { States) }\end{array}$ & $\begin{array}{l}\text { Comparando o pré e pós (com e sem } \\
\text { música), verificou-se uma diminuição } \\
\text { significativa da tensão, depressão, confusão }\end{array}$ & Moderado \\
\hline
\end{tabular}

Cuadernos de Psicología del Deporte, 20, 2 (mayo) 


\section{Efeitos psicológicos da música em praticantes de exercício}

\begin{tabular}{|c|c|c|c|c|c|c|}
\hline & $\begin{array}{l}\text { (13 mulheres; } \\
22 \pm 2.9 \text { anos) }\end{array}$ & $\begin{array}{l}\text { corrida até } 75 \% \text { da } \\
\text { frequência cardíaca } \\
\text { de reserva, sob } 2 \\
\text { condições: } \\
\text { - sem música } \\
\text { - com música } \\
\text { (repetia } \\
\text { voluntariamente até } \\
\text { final) }\end{array}$ & & $\begin{array}{l}\text { Ansiedade } \\
\text { (State Anxiety } \\
\text { Test) }\end{array}$ & $\begin{array}{l}\text { e estado de ansiedade (na condição com } \\
\text { música). }\end{array}$ & \\
\hline $\begin{array}{l}\text { Mohammadzadeh, } \\
\text { Tartibiyan e } \\
\text { Ahmadi (2008) }\end{array}$ & $\begin{array}{l}24 \text { estudantes } \\
\text { universitários } \\
(6 \text { mulheres) } \\
\text { divididos em } 2 \\
\text { grupos: } \\
-12 \text { treinados } \\
(23.31 \pm 2.06 \\
\text { anos) } \\
-12 \text { não treinados } \\
(22.96 \pm 2.31 \\
\text { anos) }\end{array}$ & $\begin{array}{l}\text { Estudo } \\
\text { Experimental: } \\
\text { Bruce Treadmill } \\
\text { Test, sob 2 } \\
\text { condições: } \\
\text { - sem música } \\
\text { - com música }\end{array}$ & $\begin{array}{l}\text { Condições } \\
\text { experimentais } \\
\text { diferentes }\end{array}$ & $\begin{array}{l}\text { Perceção de } \\
\text { Esforço (Escala de } \\
\text { Borg, 0-10) }\end{array}$ & $\begin{array}{l}\text { A perceção de esforço foi } \\
\text { significativamente menor na condição com } \\
\text { música, sobretudo nos não treinados. }\end{array}$ & Fraco \\
\hline $\begin{array}{l}\text { Nakamura, Pereira, } \\
\text { Papini, Nakamura e } \\
\text { Kokubun (2010) }\end{array}$ & $\begin{array}{l}15 \text { homens } \\
\text { praticantes de } \\
\text { exercício }(22.8 \pm \\
3.1 \text { anos })\end{array}$ & $\begin{array}{l}\text { Estudo } \\
\text { Experimental: } \\
\text { pedalar na bicicleta } \\
\text { até à exaustão, sob } 3 \\
\text { condições } \\
\text { - sem música } \\
\text { - música não } \\
\text { preferida } \\
\text { - música preferida }\end{array}$ & $\begin{array}{l}\text { Condições } \\
\text { experimentais } \\
\text { diferentes }\end{array}$ & $\begin{array}{l}\text { Perceção de } \\
\text { Esforço (Escala de } \\
\text { Borg, 6-20) }\end{array}$ & $\begin{array}{l}\text { A perceção de esforço foi } \\
\text { significativamente maior com música não } \\
\text { preferida do que nas outras duas condições. }\end{array}$ & Moderado \\
\hline $\begin{array}{l}\text { Sanchez, Moss, } \\
\text { Twist e } \\
\text { Karageorghis } \\
(2014)\end{array}$ & $\begin{array}{l}25 \text { adultos } \\
\text { praticantes de } \\
\text { exercício } \\
(11 \text { mulheres; } \\
20.8 \pm 1.3 \text { anos })\end{array}$ & $\begin{array}{l}\text { Estudo } \\
\text { Experimental: } \\
6 \text { minutos a pedalar } \\
\text { segundo cadência } \\
\text { previamente } \\
\text { selecionada por cada } \\
\text { participante, sob } 3 \\
\text { condições: } \\
\text { - sem música } \\
\text { - música sem letra } \\
\text { - música + letra } \\
\text {-múa }\end{array}$ & $\begin{array}{l}\text { Condições } \\
\text { experimentais } \\
\text { diferentes }\end{array}$ & $\begin{array}{l}\text { Perceção de } \\
\text { Esforço (Escala de } \\
\text { Borg, 6-20) } \\
\text { Afetos (Positive } \\
\text { and Negative } \\
\text { Affect Schedule) }\end{array}$ & $\begin{array}{l}\text { Não houve diferenças significativas na } \\
\text { perceção de esforço nem nos afetos entre } \\
\text { condições (mas aumentaram os afetos } \\
\text { positivos e diminuíram os negativos, } \\
\text { comparando os valores pré e após). }\end{array}$ & Moderado \\
\hline
\end{tabular}




\section{Marques \& Carraça}

\begin{tabular}{|c|c|c|c|c|c|c|}
\hline $\begin{array}{l}\text { Shaulov e Lufi } \\
\text { (2009) }\end{array}$ & $\begin{array}{l}28 \text { adultos } \\
\text { praticantes de } \\
\text { exercício } \\
(14 \text { mulheres; } \\
36.8 \pm 9.5 \text { anos }) \\
\text { divididos em } 2 \\
\text { grupos: } \\
-14 \text { com } \\
\text { experiência } \\
-14 \text { sem } \\
\text { experiência } \\
\text { em ciclismo }\end{array}$ & $\begin{array}{l}\text { Estudo } \\
\text { Experimental: } \\
\text { - sem música e } \\
\text { pouca luz - sem } \\
\text { música e com luz } \\
\text { total } \\
\text { - com música e } \\
\text { pouca luz } \\
\text { - com música e com } \\
\text { luz total }\end{array}$ & $\begin{array}{l}\text { Condições } \\
\text { experimentais } \\
\text { diferentes }\end{array}$ & $\begin{array}{l}\text { Emoções e } \\
\text { satisfação } \\
\text { (Assessment of } \\
\text { Activity, } \\
\text { Satisfaction, and } \\
\text { Feelings) }\end{array}$ & $\begin{array}{l}\text { O prazer foi maior na presença de música. } \\
\text { Os valores de prazer foram mais elevados e } \\
\text { os de cansaço mais reduzidos na condição } \\
\text { com música e luz reduzida. }\end{array}$ & Fraco \\
\hline $\begin{array}{l}\text { Stork, Kwan, Gibala } \\
\text { e Martin Ginis } \\
\text { (2014) }\end{array}$ & $\begin{array}{l}20 \text { adultos } \\
\text { praticantes de } \\
\text { exercício: } \\
8 \text { homens } \\
(21.2 \pm 0.9 \text { anos }) \\
\text { e } \\
10 \text { mulheres } \\
(22.5 \pm 4.3 \text { anos })\end{array}$ & $\begin{array}{l}\text { Estudo } \\
\text { Experimental: } \\
\text { Teste de Wingate } \\
\text { em cicloergómetro } \\
\text { sob duas condições: } \\
\text { - sem música } \\
\text { - com música }\end{array}$ & $\begin{array}{l}\text { Brunel Music } \\
\text { Rating Inventory } \\
2\end{array}$ & $\begin{array}{l}\text { Perceção de esforço } \\
\text { (Escala de Borg, 0- } \\
\text { 10) } \\
\text { Afetos (Feeling } \\
\text { Scale) } \\
\text { Motivação (Task } \\
\text { Motivation) } \\
\text { Prazer/diversão } \\
\text { (Physical Activity } \\
\text { Enjoyment Scale) }\end{array}$ & $\begin{array}{l}\text { Não houve diferenças significativas na } \\
\text { perceção de esforço, respostas afetiva e } \\
\text { motivacional entre as condições. Houve } \\
\text { diferenças significativas no prazer/diversão } \\
\text { após o exercício, sendo maior na condição } \\
\text { com música. Apesar de escolhidas pelos } \\
\text { participantes, as músicas não tiveram uma } \\
\text { componente motivacional muito elevada. }\end{array}$ & Moderado \\
\hline $\begin{array}{l}\text { Szmedra e } \\
\text { Bacharach (1998) }\end{array}$ & $\begin{array}{l}10 \text { homens } \\
\text { praticantes de } \\
\text { exercício }(25.1 \pm 6 \\
\text { anos) }\end{array}$ & $\begin{array}{l}\text { Estudo } \\
\text { Experimental: } \\
\text { sessão de exercício } \\
\text { sub-máximo sob } 2 \\
\text { condições: } \\
\text { - sem música } \\
\text { - com música }\end{array}$ & $\begin{array}{l}\text { Condições } \\
\text { experimentais } \\
\text { diferentes }\end{array}$ & $\begin{array}{l}\text { Perceção de } \\
\text { Esforço (Escala de } \\
\text { Borg, 6-20 }\end{array}$ & $\begin{array}{l}\text { A perceção de esforço foi } \\
\text { significativamente menor com música do } \\
\text { que sem música. }\end{array}$ & Fraco \\
\hline $\begin{array}{l}\text { Tiev, Manire, } \\
\text { Robertson e Barbara } \\
\text { (2010) }\end{array}$ & $\begin{array}{l}20 \text { adultos } \\
\text { praticantes de } \\
\text { exercício } \\
(10 \text { mulheres; } \\
23.4 \pm 2.4 \text { anos })\end{array}$ & $\begin{array}{l}\text { Estudo } \\
\text { Experimental: } \\
20 \text { minutos de } \\
\text { corrida a velocidade } \\
\text { constante, escolhida } \\
\text { por cada }\end{array}$ & $\begin{array}{l}\text { Condições } \\
\text { experimentais } \\
\text { diferentes }\end{array}$ & $\begin{array}{l}\text { Perceção de } \\
\text { Esforço (OMNI } \\
\text { Perceived Exertion } \\
\text { Scale) }\end{array}$ & $\begin{array}{l}\text { A perceção de esforço durante o exercício } \\
\text { foi menor na condição com música e o } \\
\text { prazer/diversão foi maior. }\end{array}$ & Moderado \\
\hline
\end{tabular}




\section{Efeitos psicológicos da música em praticantes de exercício}

\begin{tabular}{|c|c|c|c|c|c|c|}
\hline & & $\begin{array}{l}\text { participante, sob } \\
\text { duas condições: } \\
\text { - com diálogo } \\
\text { - com música } \\
\text { (todos fizeram as } \\
\text { duas provas, por } \\
\text { ordem aleatória) }\end{array}$ & & $\begin{array}{l}\text { Prazer/diversão } \\
\text { (Modified 10-point } \\
\text { Likert Scale) }\end{array}$ & & \\
\hline $\begin{array}{l}\text { Young, Sands e } \\
\text { Jung (2009) }\end{array}$ & $\begin{array}{l}20 \text { mulheres } \\
\text { praticantes de } \\
\text { futebol } \\
(20.4 \pm 1.0 \text { anos })\end{array}$ & $\begin{array}{l}\text { Estudo } \\
\text { Experimental: } \\
\text { corrida até à } \\
\text { exaustão sob duas } \\
\text { condições: } \\
\text { - sem música } \\
\text { - com música }\end{array}$ & $\begin{array}{l}\text { Condições } \\
\text { experimentais } \\
\text { diferentes }\end{array}$ & $\begin{array}{l}\text { Perceção de } \\
\text { Esforço (Escala de } \\
\text { Borg, 6-20) }\end{array}$ & $\begin{array}{l}\text { Não houve diferenças significativas na } \\
\text { perceção de esforço entre as duas condições. }\end{array}$ & Fraco \\
\hline
\end{tabular}




\section{Marques \& Carraça}

\section{DISCUSSÃO}

O objetivo desta revisão sistemática foi analisar os efeitos que a presença de música poderia ter durante a prática de exercício físico em variáveis psicológicas como a motivação, a resposta afetiva ao esforço, a vitalidade, e a perceção subjetiva de esforço, entre outras. Os resultados da presente revisão realçam o reduzido número de estudos existentes para algumas das variáveis e, paralelamente, a inconsistência dos efeitos encontrados, com exceção do observado para a perceção subjetiva de esforço. Concretamente, verificou-se que apenas 11 estudos analisaram os efeitos da presença de música na resposta afetiva ao exercício, sendo que só cerca de metade revelaram efeitos positivos $(n=6)$. No que respeita à motivação, somente 4 estudos avaliaram os efeitos da presença de música, mas apesar do número reduzido, os resultados foram relativamente consistentes e positivos na sua generalidade (em 3 dos 4 estudos). Similarmente, os efeitos positivos da música no aumento do prazer/diversão durante a prática de exercício foram consistentes, apesar de derivarem de apenas 3 estudos. Relativamente à percepção subjetiva de esforço, foram encontrados bastantes mais estudos $(n=22)$, tendo a maior parte $(n=14)$ sugerido a inexistência de efeitos da presença de música na redução da percepção subjetiva de esforço. Este resultado em concreto parece contradizer a literatura que sugere que a música, pela distração do possível mal-estar derivado do esforço, evocação de emoções e boas recordações, ou simplesmente pelo facto de gostarmos da playlist em si, possa ter na redução da perceção subjetiva de esforço (Hutchinson \& Karageorghis, 2013; Karageorghis \& Jones, 2014).

Os resultados observados e as suas disparidades poderão ter várias explicações de caráter metodológico como a utilização de protocolos diferenciados (condições experimentais, sessões de exercício, tempo do estudo, entre outros aspetos), o recurso a instrumentos diferentes entre os estudos para a avaliação de uma mesma variável (por exemplo, a Feeling Scale ou o Positive and Negative Affect Schedule usados para avaliar a resposta afetiva), ou a variabilidade nas características das amostras (i.e., níveis de aptidão física, tempo de prática, etc.). Por exemplo, é de esperar que uma pessoa que já pratique exercício regularmente não veja a música como um fator extra tão motivador como alguém que se tornou fisicamente ativo há pouco tempo, uma vez que a primeira já deverá estar bem motivada para manter a sua prática. Relativamente à perceção subjetiva de esforço, poder-se-á pensar que alguém que não esteja habituado a exercitar-se beneficie mais da música como um fator de distração da dor e do cansaço do que alguém treinado e habituado ao exercício. Isto porque a redução da perceção de esforço está fortemente relacionada com condições que incluam estímulos que retirem o foco da nossa atenção das sensações físicas durante o exercício como a fadiga (Nethery, 2000).

Possíveis associações entre várias das variáveis psicológicas analisadas neste estudo e que permanecem relativamente desconhecidas podem também ajudar a explicar a falta de consistência nos resultados. Por exemplo, a perceção de esforço e a resposta afetiva são elementos que não são isomorfos, ou seja, apesar de ligados, são distintos e podem sofrer variações em sentidos contrários dependendo das condições (Boutcher \& Trenske, 1990; Elliott, Carr \& Orme, 2005). Por outras palavras, numa condição de exercício mais intensa e com música que leve a uma perceção de esforço maior, os níveis de afetos positivos (e não os negativos como é mais habitual) poderão ser mais elevados, pelo contentamento derivado dos resultados que estão a ser obtidos (Edworthy \& Waring, 2006). Além disso, a música por si só pode aumentar a motivação intrínseca, o que também poderá ter efeito na resposta afetiva, dado estas duas variáveis estarem ligadas (Elliott, Carr \& Orme, 2005; Hutchinson, Karageorghis \& Jones, 2015).

É também possível que a interferência de outras variáveis nas associações entre a música e cada uma das variáveis psicológicas em análise possa contribuir para os resultados observados. Relativamente à resposta afetiva ao esforço, o aumento dos afetos positivos poderá ser consequência de um aumento do rendimento/performance que poderá advir da presença de música, mas não diretamente da presença de música, interferindo nas relações analisadas aqui nesta revisão. Porém, e apesar destes efeitos de mediação precisarem de ser estudados com maior profundidade, o que parece acontecer na maioria dos casos é apenas a verificação dos níveis de afetos positivos e negativos respeitantes à prática de exercício com e sem música, negligenciando-se a análise das causas subjacentes a este aumento ou redução dos afetos, que efetivamente 


\section{Efeitos psicológicos da música em praticantes de exercício}

poderão ser múltiplas e independentes da presença ou ausência de música (Elliott, Carr \& Savage, 2004).

É ainda importante referir que a interpretação dos resultados das diversas investigações em que a música é uma das variáveis são ainda dificultados pelo facto de esta ter inúmeras características específicas, como o estilo (pop, rock, clássica, jazz, entre outras), a velocidade (normalmente referido como número de batimentos por minuto; bpm), o volume (mais alto ou mais baixo), entre outras. Tudo isto leva a uma panóplia de variantes musicais, que podem interferir diferentemente nas respostas psicológicas das pessoas. Também o facto de a música ter ou não letra associada requer mais investigações futuras (Sanchez et al., 2014). No entanto, realça-se que os efeitos positivos ou negativos provenientes da música podem nem estar relacionados com estas características, mas sim com motivos como o reavivar de boas ou más memórias ou até mesmo por nos fazer fantasiar e pensar num futuro mais agradável (Boutcher \& Trenske, 1990).

Além de tudo isto, as preferências pessoais de cada um podem interferir com a maneira como a pessoa lidará com a presença de música durante a prática de exercício. A mesma trilha sonora pode ter impactos diferentes em pessoas com gostos musicais diferentes (Gabana et al., 2015; Hutchinson \& Karageorghis, 2013). Pesquisas futuras deverão ter isso em consideração e ter grupos experimentais que façam (vs. não) as suas próprias escolhas musicais.

Limitações da evidência. O número de estudos centrados na análise dos efeitos da presença de música em variáveis psicológicas foi muito reduzido, sendo que a maioria dos artigos existentes analisa variáveis físicas como o rendimento, a resistência e a frequência cardíaca. Também se verifica que os estudos experimentais se têm focado em sessões de exercício aeróbio e raramente no trabalho de força e que a perceção subjetiva de esforço tem sido a variável psicológica mais estudada, o que estará potencialmente ligado à facilidade com que esta é medida (Escala de Borg, na grande maioria dos casos). Finalmente, será importante considerar a intensidade do exercício realizado quando se analisa o efeito da música nos fatores psicológicos. Apenas dois dos estudos identificados tiveram este aspecto em consideração (Brownley, McMurray \& Hackney, 1995; Hutchinson, Karageorghis \& Jones, 2015), mas usando protocolos diferenciados, impossibilitando assim a análise do papel da intensidade do exercício realizado nos efeitos psicológicos induzidos pela presença de música na presente revisão. Similarmente, a análise de outros moderadores dos efeitos da música foi escassa. Deste modo, futuramente, é importante que se procurem considerar os aspectos mencionados, procurando-se a utilização de protocolos mais uniformizados, mas que contemplem diferentes intensidades de treino, preferências musicais (vs. impostas), que explorem diferentes características da música e que utilizem instrumentos mais estandardizados. Será também importante controlar para o efeito da experiência prévia na prática da modalidade analisada, visto que esta pode influenciar a percepção de competência (Zarceño, Vilella, Serrano-Rosa \& López, 2017), e portanto mascarar os efeitos da presença de música.

\section{CONCLUSÕES}

A presente revisão sistemática mostrou que o estudo do recurso à música durante a realização de exercício é algo que deverá ser aprofundado em investigações futuras dada a variabilidade observada não só em termos de resultados, mas também de metodologias. A perceção subjetiva de esforço não parece ser influenciada pela presença de música, mas os resultados relativos às restantes variáveis foram inconsistentes, também fruto do reduzido número de estudos por variável. Se há já uma quantidade elevada de investigações que associam a existência de música a maiores produções de trabalho físico (e.g., períodos de tempo até à exaustão maiores), é importante que estudos futuros deem prioridade ao estudo do efeito psicológico da presença da música durante a prática de exercício. Recomenda-se que futuramente se procurem utilizar protocolos mais uniformizados e instrumentos mais estandardizados, que analisem diferentes intensidades de treino, preferências musicais (vs. impostas) e características da música. Conseguindo-se comprovar futuramente que o recurso à música tem vantagens nas variáveis referidas, acredita-se que este poderá ser um recurso para potenciar a adesão continuada à prática de exercício físico regular, combatendo os elevados níveis de sedentarismo da população em geral. 


\section{Marques \& Carraça}

\section{IMPLICAÇÕES PRÁTICAS}

A variabilidade de resultados encontrados nesta revisão impossibilita afirmar convictamente que a presença de música durante a realização de exercício poderá (ou não) ser um coadjuvante da adoção sustentada do exercício, por intermédio dos seus efeitos nas variáveis psicológicas analisadas. Apesar de alguns estudos apontarem nesse sentido, como por exemplo os estudos que mostraram aumentos no prazer/diversão ou nos níveis de motivação, a maior parte das variáveis foram analisadas muito poucas vezes para se poderem retirar conclusões válidas e robustas. Deste modo, ainda é cedo para traçar linhas de ação ou delinear recomendações baseadas em evidência suficiente e consistente. Do que se pode depreender até à data, realizar exercício na presença de música parece ter efeitos positivos, principalmente ao nível do prazer e da motivação, ou na pior das hipóteses nenhum efeito, pelo que a sua utilização durante a prática de exercício não parece ser desaconselhável para a promoção de uma adoção sustentada ao exercício.

\section{REFERÊNCIAS}

1. Atan, T. (2013). Effect of Music. Biology of Sport on Anaerobic Exercise Performance, 30(1), 3539.

2. Berger, B., Pargman, D., \& Weinberg, R. (2002). Foundations of Exercise Psychology. Morgantown: Fitness Information Techology, Inc.

3. Bigliassi, M., Estanislau, C., Carneiro, J. G., Dias Kanthack, T. F., \& Altimari, L. R. (2013). Música: un recurso psicofisiológico para el ejercicio físico y deporte. Archivos de Medicina Del Deporte: Revista de La Federación Española de Medicina Del Deporte y de La Confederación Iberoamericana de Medicina Del Deporte, (157), 311-320.

https://doi.org/10.1016/j.ramd.2014.10.050

4. Bood, R. J., Nijssen, M., van der Kamp, J., \& Roerdink, M. (2013). The Power of AuditoryMotor Synchronization in Sports: Enhancing Running Performance by Coupling Cadence with the Right Beats. PLoS ONE, 8(8). https://doi.org/10.1371/journal.pone.0070758
5. Boutcher, S. H., \& Trenske, M. (1990). The Effects of Sensory Deprivation and Music on Perceived Exertion and Affect During Exercise. Journal of Sport \& Exercise Psychology, 12, 167-176. https://doi.org/10.1123/jsep.12.2.167

6. Brohmer, R., \& Becker, C. (2006). Effects of Music on Wingate Performance. Journal of Undergraduate Kinesiology Research, 2(1), 1-7.

7. Brownley, K. A., McMurray, R. G., \& Hackney, A. C. (1995). Effects of Music on Physiological and Affective Responses to Graded Treadmill Exercise in Trained and Untrained Runners. International Journal of Psychophysiology, 19(3), 193-201. https://doi.org/10.1016/01678760(95)00007-F

8. Concha-Viera, A.M., Cuevas-Ferrer, R., Campos-Romero, P., \& González-Hernández, J. (2017). Recursos Motivacionales para la Autorregulación en la Actividad Física en Edad Universitária. Cuadernos de Psicología del Deporte, 17(2), 27-34. https://doi.org/10.4321/s157884232015000200004

9. Crust, L. (2008). Perceived importance of components of asynchronous music during circuit training. Journal of Sports Sciences, 26(14),

1547-1555. https://doi.org/10.1080/02640410802315427

10. Edworthy, J., \& Waring, H. (2006). The effects of music tempo and loudness level on treadmill exercise. Ergonomics, 49(15), 1597-1610. https://doi.org/10.1080/00140130600899104

11. Elliott, D., Carr, S., \& Orme, D. (2005). The effect of motivational music on sub-maximal exercise. European Journal of Sport Science, $5(2)$, 97-106. https://doi.org/10.1080/17461390500171310

12. Elliott, D., Carr, S., \& Savage, D. (2004). Effects of Motivational Music on Work Output and Affective Responses During Sub-maximal Cycling of a Standardized Perceived Intensity. Journal of Sport Behavior, 27(2), 134-147.

13. Eurobarometer. (2017). Special Eurobarometer 472: sport and physical activity: report. Special Eurobarometer 472 (pp. 1-133). Brussels: Directorate-General for Education and Culture. 


\section{Efeitos psicológicos da música em praticantes de exercício}

Directorate-General for Communication. https://doi.org/10.2766/73002

14. Fernández-Ríos, L., \& Buela-Casal, G. (2009). Standards for the preparation and writing of Psychology review articles. International Journal of Clinical and Health Psychology, 9(2):329-344.

15. Gabana, N. T., Van Raalte, J. L., Hutchinson, J. C., Brewer, B. W., \& Petitpas, A. J. (2015). The Effects of Music and a Coxswain on Attentional Focus, Perceived Exertion, Motivation, and Performance During a 1,000 m Ergometer Rowing Sprint. Journal of Applied Sport Psychology, 27(3), 288-300. https://doi.org/10.1080/10413200.2014.993775

16. Garber, C., Blissmer, B., Deschenes, M., Franklin, B., Lamonte, M., Lee, I-Min., ... Swain, D. (2011). Quantity and quality of exercise for developing and maintaining cardiorespiratory, musculoskeletal, and neuromotor fitness in apparently healthy adults: Guidance for prescribing exercise. Medicine \& Science in Sports \& Exercise, 43(7), 1334-59. https://doi.org/10.1249/mss.0b013e318213fefb

17. Guerrero, E. A., Fajardo, G. A. \& Corona, J. A. A. (2017). Explorando la Intensidad de la Música en la Frecuencia Cardiaca, Esfuerzo Percibido y Rendimiento Físico Durante el Ejercicio SubMáximo. Kronos, 16(2). https://doi.org/10.15517/pensarmov.v1i2.429

18. Guillén, F., \& Ruiz-Alfonso, Z. (2015). Influence of music on physical performance, perceived exertion and motivation. Revista Internacional de Medicina y Ciencias de La Actividad Fisica y Del Deporte, 15(60). https://doi.org/10.15366/rimcafd2015.60.006

19. Halfmann, V., \& Smith, S. (2014). Effect of Listening to 140 BPM Music on Sationary Cycling Time. Missouri Journal of Health, Physical Education, Recreation \& Dance, 24, 5$10 . \quad$ Retrieved from http://search.ebscohost.com/login.aspx?direct=tr $\mathrm{ue} \& \mathrm{db}=\mathrm{s} 3 \mathrm{~h} \& \mathrm{AN}=113834134 \&$ lang $=\mathrm{es} \& \mathrm{site}=\mathrm{eh}$ ost-live

20. Hutchinson, J. C., \& Karageorghis, C. I. (2013). Moderating influence of dominant attentional style and exercise intensity on responses to asynchronous music. Journal of Sport and Exercise Psychology, 35, 625-643. https://doi.org/10.1123/jsep.35.6.625

21. Hutchinson, J. C., Karageorghis, C. I. \& Jones, L. (2015). See Hear: Psychological Effects of Music and Music-Video During Treadmill Running. Annals of Behavioral Medicine, 49(2), 199-211. https://doi.org/10.1007/s12160-014-9647-2

22. Jarraya, M., Chtourou, H., Aloui, A., Hammouda, O., Chamari, K., Chaouachi, A., \& Souissi, N. (2012). The effects of music on high-intensity short-term exercise in well trained athletes. Asian Journal of Sports Medicine, 3(4), 233-238. https://doi.org/10.5812/asjsm.34543

23. Karageorghis, C. I., \& Jones, L. (2014). On the stability and relevance of the exercise heart ratemusic-tempo preference relationship. Psychology of Sport and Exercise, 15(3), 299-310. https://doi.org/10.1016/j.psychsport.2013.08.004

24. Karageorghis, C. I., \& Terry, P. C. (1997) The Psychophysical Effects of Music in Sport and Exercise: A Review. Journal of Sport Behavior 20(1), 54-68

25. Karageorghis, C. I., Mouzourides, D. A., Priest, D.-L., Sasso, T. a, Morrish, D. J., \& Walley, C. J. (2009). Psychophysical and ergogenic effects of synchronous music during treadmill walking. Journal of Sport \& Exercise Psychology, 31(1), 18-36. https://doi.org/10.1123/jsep.31.1.18

26. Karageorghis, C. I., Priest, D. L., Williams, L. S., Hirani, R. M., Lannon, K. M., \& Bates, B. J. (2010). Ergogenic and psychological effects of synchronous music during circuit-type exercise. Psychology of Sport and Exercise, 11(6), 551559.

https://doi.org/10.1016/j.psychsport.2010.06.004

27. Liberati A, Altman DG, Tetzlaff J, Mulrow C, Gøtzsche PC, Ioannidis JP, et al. (2009) The PRISMA statement for reporting systematic reviews and meta-analyses of studies that evaluate health care interventions: explanation and elaboration. PLoS Med, 6(7): e1000100. https://doi.org/10.1371/journal.pmed.1000100

28. Lim, H. B. T., Atkinson, G., Karageorghis, C. I., \& Eubank, M. R. (2009). Effects of differentiated music on cycling time trial. International Journal 


\section{Marques \& Carraça}

of Sports Medicine, 30(6), 435-442. https://doi.org/10.1055/s-0028-1112140

29. Lim, H. B. T., Karageorghis, C. I., Romer, L. M., \& Bishop, D. T. (2014). Psychophysiological effects of synchronous versus asynchronous music during cycling. Medicine and Science in Sports and Exercise, 46(2), 407-413. https://doi.org/10.1249/MSS.0b013e3182a6378c

30. Lima-Silva, A. E., Silva-Cavalcante, M. D., Pires, F. O., Bertuzzi, R., Oliveira, R. S. F., \& Bishop, D. (2012). Listening to music in the first, but not the last $15 \mathrm{~km}$ of a $5-\mathrm{km}$ running trial alters pacing strategy and improves performance. International Journal of Sports Medicine, 33(10), 813-818. https://doi.org/10.1055/s-00321311581

31. Lopes-Silva, J. P., Lima-Silva, A. E., Bertuzzi, R., \& Silva-Cavalcante, M. D. (2015). Influence of music on performance and psychophysiological responses during moderateintensity exercise preceded by fatigue. Physiology and Behavior, 139, 274-280. https://doi.org/10.1016/j.physbeh.2014.11.048

32. Macone, D., Baldari, C., Zelli, A., \& Guidetti, L. (2006). Music and Physical Activity in Psychological Well-Being. Perceptual \& Motor Skills, 103(1), 285-295. https://doi.org/10.2466/pms.103.1.285-295

33. Miguel-Calvo, J.M., Gallo, I.S., Mozas-Majano, O., \& Hernández-López, J.M. (2011). Efecto del ejercicio físico en la productividad laboral y el bienestar. Revista de Psicología del Deporte, 20(2), 589-604. https://doi.org/10.5093/rpadef2018a6

34. Mohammadzadeh, H., Tartibiyan, B., Ahmadi, A., Mohammadzadeh, H., Tartibiyan, B., \& Ahmadi, A. (2008). the Effects of Music on the Perceived Exertion Rate and Performance of Trained and Untrained Individuals During Progressive Exercise. Physical Education and Sport, 6(1), 67-74.

35. Moreno, J.A., \& Martínez, A. (2006). Importancia de la teoría de la Autodeterminación en la práctica físicodeportiva: fundamentos e implicaciones prácticas. Cuadernos de Psicología del Deporte,
6(1), 39-54. https://doi.org/10.4321/s157884232013000100005

36. Nakamura, P. M., Pereira, G., Papini, C. B., Nakamura, F. Y., \& Kokubun, E. (2010). Effects of Preferred and Nonpreferred Music on Continuous Cycling Exercise Performance. Perceptual \& Motor Skills, 110(1), 257-264. https://doi.org/10.2466/pms.110.1.257-264

37. Nethery V. M. (2000). Competition between internal and external sources of information during exercise: influence on RPE and the impact of the exercise load. Journal of Sports Medicine and Physical Fitness, 42(2), 172-178.

38. Pedersen, B. K., \& Saltin, B. (2015). Exercise as medicine - evidence for prescribing exercise as therapy in 26 different chronic diseases. Scandinavian Journal of Medicine \& Science in Sports, 25, 1-72. https://doi.org/10.1111/sms.12581

39. Rhodes, R.E., \& Kates, A. (2015). Can the Affective Response to Exercise Predict Future Motives and Physical Activity Behavior? A Systematic Review Annals of Behavioral Medicine, 49 (5), 715-731. https://doi.org/10.1007/s12160-015-9704-5

40. Ryan, R. M., \& Deci, E. L. (2017). Selfdetermination theory: Basic psychological needs in motivation, development, and wellness. Guilford https://doi.org/10.7202/1041847ar

41. Sanchez, X., Moss, S. L., Twist, C., \& Karageorghis, C. I. (2014). On the role of lyrics in the music-exercise performance relationship. Psychology of Sport and Exercise, 15(1), 132138.

https://doi.org/10.1016/j.psychsport.2013.10.007

42. Shaulov, N., \& Lufi, D. (2009). Music and light during indoor cycling. Perceptual \& Motor Skills, 108 , 597-607. https://doi.org/10.2466/pms.108.2.597-607

43. Simpson, S. D., \& Karageorghis, C. I. (2006). The effects of synchronous music on 400-m sprint performance. Journal of Sports Sciences, 24(10), 1095-1102. https://doi.org/10.1080/02640410500432789 


\section{Efeitos psicológicos da música em praticantes de exercício}

44. Stork, M. J., Kwan, M. Y. W., Gibala, M. J., \& Martin Ginis, K. A. (2015). Music enhances performance and perceived enjoyment of sprint interval exercise. Medicine and Science in Sports and Exercise, 47(5), 1052-1060. https://doi.org/10.1249/MSS.000000000000049 4

45. Souza, Y. R., \& Silva, E. R. (2010). Efeitos psicofísicos da música no exercício: uma revisão. Revista Brasileira de Psicologia Do Esporte, 3(2), 33-45.

46. Szmedra, L., \& Bacharach, D. W. (1998). Effect of music on perceived exertion, plasma lactate, norepinephrine and cardiovascular hemodynamics during treadmill running. International Journal of Sports Medicine, 19(1), 32-37. https://doi.org/10.1055/s-2007-971876

47. Teixeira, P. J., Carraça, E.V., Silva, M.N., Markland, D., \& Ryan, R. (2012). Exercise, Physical Activity, and Self-Determination Theory: A systematic Review. International Journal of Behavioral Nutrition and Physical Activity, 9:78-108. https://doi.org/10.1186/14795868-9-78

48. Thakare, A. E., Mehrotra, R., \& Singh, A. (2017). Effect of music tempo on exercise performance and heart rate among young adults. International Journal of Physiology, Pathophysiology and Pharmacology, 9(2), 35-39. https://doi.org/10.4103/1658-5127.141993

49. Tiev, M., Manire, S. A., Robertson, R. J., \& Barbara, W. (2010). Effect of music and dialogue on perception of exertion, enjoyment, and metabolic responses during exercise. International Journal of Fitness, 6(2), 45-52.

50. Thomas, B.H., Ciliska, D., Dobbins, M., Micucci, S. (2004). A process for systematically reviewing the literature: providing the research evidence for public health nursing interventions. Worldviews on Evidence-Based Nursing, 1:176-184. https://doi.org/10.1111/j.1524475x.2004.04006.x

51. World Health Organization (2010). Global recommendations on physical activity for health. Retrieved from https://www.who.int/dietphysicalactivity/globalPA-recs-2010.pdf

52. Young, S. C., Sands, C. D., \& Jung, A. P. (2009). Effect of music in female college Soccer players during a maximal treadmill test. International Journal of Fitness, 5(2), 31-36. Retrieved from http://libproxy.cortland.edu/login?url=http://sear ch.ebscohost.com/login.aspx direct $=$ true $\& \mathrm{db}=\mathrm{s} 3$ h\&AN=44137711\&site $=$ eds-live

53. Zarceño, E.L., Vilella, S.B., Serrano-Rosa, M.A., \& López, N.P. (2017). Motivación y toma de decisiones en voleibol: Influencia de los años de experiencia. Revista de Psicología Aplicada al Deporte y al Ejercicio Físico, 1, e4, 1-10. https://doi.org/10.5093/rpadef2017a4 